\title{
Recent Trends in Western European Income Convergence
}

\author{
Donghyun Park \\ Nanyang Business School Nanyang Technological University
}

\begin{abstract}
In the postwar era, economic interaction and integration among Western European countries has grown rapidly. We examine whether those close and growing linkages have led to inter-country income convergence in Western Europe during 1960-2000. We find clear empirical evidence of convergence. This provides strong support for the notion that Western Europe constitutes a convergence club.
\end{abstract}

- JEL Classification: D31, F15, F43

- Key Words: Convergence, Economic Integration, Western Europe

\section{Introduction}

In this paper, we define Western Europe to be the 15 member countries of the European Union (EU) plus Switzerland, Norway and Iceland. Economic interaction has grown rapidly among the economies of Western Europe in the postwar era. Such interaction encompasses ever-increasing flows of goods, services and capital within the region. The region depends heavily on itself for export and import markets, capital and technology, and management know-how and skills. Extensive and growing intra-regional economic linkages have nurtured and promoted economic integration, or the removal of barriers to the movements of goods and services, capital and labor. The ever-closer integration has occurred mainly within the framework of the EU, which is the most advanced form of international economic integration in the world today.

Economic convergence refers to the narrowing of income gaps among

\footnotetext{
*Corresponding address: Donghyun Park, Nanyang Business School, Nanyang Technological University, Singapore 639798, Tel.: +65-6790-6130, Fax.: +65-6792-4217, E-mail: adpark@ntu.edu.sg (C2002-Center for International Economics, Sejong Institution, All Rights Reserved.
} 
countries. Convergence requires that poorer countries grow faster than richer countries. The underlying intuition is based on the Solow-Swan neoclassical growth model, according to which the combination of diminishing marginal returns to capital and the differences in relative endowments of capital in richer and poorer countries induces the flow of capital from the former to the latter. The flow of capital, in turn, promotes rapid growth and narrowing of the income gap. There is a large and expanding empirical literature on convergence. ${ }^{1}$ For broad samples of countries, the overall evidence generally fails to support convergence.

The evidence in favor of convergence is considerably stronger for more limited groups of countries. In particular, there is some evidence that indicates convergence among countries at similar levels of economic development. Ben David (1998) and Chatterji (1992), among others, find empirical evidence of convergence among the worlds richest and poor countries. Galor (1996) and Quah (1997) provide theoretical justifications for the possibility that convergence will occur among subsets as opposed to broad samples of countries. This theoretical possibility is formally known as the convergence club hypothesis.

In this note, we empirically examine whether or not the intercountry income distribution of Western Europe has been becoming more equal during 1960-2000. That is, whether or not the region constitutes a convergence club. The increasingly extensive interaction among the regional economies noted above implies opportunities for the poorer economies to catch up with the richer economies. For example, closer integration would accelerate flows of capital from richer European countries to poorer ones. There is a two-way relationship between convergence and economic integration. While integration promotes convergence, convergence also promotes integration by, for example, fostering intra-industry trade. Economic linkages resulting from geographical proximity may promote convergence clubs.

\section{Data and Methodology}

Our primary data source is the Penn World Tables (PWT) version 5.6. Summers and Heston (1991) provide a comprehensive explanation of this data set. The unique feature of PWT is that all economic variables are denominated in a common set of prices and in a common currency. This allows for meaningful

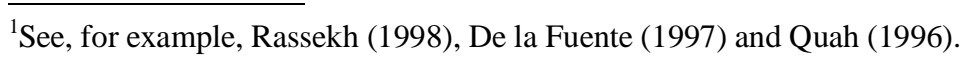


international comparisons of income. We examine the data at 5-year intervals during 1960-2000. Our variables of interest are population and real GDP per capita of each country. Our total sample comprises the $15 \mathrm{EU}$ member states Austria, Belgium, Denmark, Finland, France, Germany, Greece, Ireland, Italy, Luxembourg, Netherlands, Portugal, Spain, Sweden and the United Kingdom plus Switzerland, Norway and Iceland.

Theil (1967) developed two widely used measures of inequality. Both Theil indices satisfy all the standard ideal properties of an inequality measure and are derived from the Shannon measure of entropy in information theory. The first index, the Theil entropy index $T$, reflects the expected information of a message that transforms income shares of a country into population shares of the country. It assumes a minimum value of 0 when there is complete equality and a maximum value of $\ln (n)$ when there is complete inequality so that all income accrues to only one country. For our purposes, the Theil entropy index is as follows:

$$
T=\sum_{i=1}^{n} y_{i} \ln \left(y_{i} / p_{i}\right)
$$

where $y_{i}$ is the share of country $i$ in the total income of all countries in the sample and $\mathrm{p}_{\mathrm{i}}$ is the share of country $i$ in the total population of all countries in the sample.

The second index, which we call Theil's second measure $L$, is analogous to the Theil entropy except that the role of income shares and population shares are reversed. Therefore, $L$ reflects the expected information of a message that transforms population shares of a country into income shares of the country. The value of $L$ also ranges from a minimum of 0 to a maximum of $\ln (\mathrm{n})$. There is no reason to reason to expect the value of $T$ and $L$ to be the same. For our purposes, we can express Theils second measure $L$ as follows:

$$
L=\sum_{i=1}^{n} p_{i} \ln \left(p_{i} / y_{i}\right)
$$

\section{Results}

Table 1 below reports the values of the Theil entropy index $T$ in (1) and Theils second measure $L$ we have computed. $T_{1}$ and $L_{1}$ are the values for the 18 countries of Western Europe while $T_{2}$ and $L_{2}$ are the values for the 15 countries of the EU. 
Table 1. Theil Inequality Indices for Western Europe and EU, 1960-2000

\begin{tabular}{|ccccc|}
\hline Year & $T_{1}$ & $L_{1}$ & $T_{2}$ & $L_{2}$ \\
\hline 1960 & 0.0435 & 0.0511 & 0.0416 & 0.0495 \\
1965 & 0.0317 & 0.0365 & 0.0297 & 0.0348 \\
1970 & 0.0233 & 0.0266 & 0.0215 & 0.0250 \\
1975 & 0.0169 & 0.0189 & 0.0160 & 0.0181 \\
1980 & 0.0185 & 0.0209 & 0.0179 & 0.0203 \\
1985 & 0.0201 & 0.0229 & 0.0193 & 0.0222 \\
1990 & 0.0140 & 0.0157 & 0.0136 & 0.0153 \\
1995 & 0.0126 & 0.0139 & 0.0119 & 0.0130 \\
2000 & 0.0091 & 0.0100 & 0.0091 & 0.0099 \\
\hline
\end{tabular}

Note: $T_{1}$ and $L_{1}$ are values for Western Europe while $T_{2}$ and $L_{2}$ are values for EU.

Fig. 1. Theil Inequality Indices for Western Europe and EU, 1960-2000.



The trends of both Theil indices strongly suggest that inter-country income inequality has been falling in Western Europe and EU. All four indices fall substantially during the sample period. Furthermore, they do so continuously throughout the sample period except for 1980-1985. Figure 1 below reproduces the results in Table 1.

\section{Conclusion}

In this note, we empirically examine the issue of whether the close and growing economic interaction and integration among Western European economies has led to inter-country income convergence within the region. Our evidence clearly lends 
empirical support for convergence among Western European countries. Our results indicate that the poorer countries of the region grew significantly faster higher than the richer countries, resulting in a sharp decline in inter-country income inequality. It remains to be seen whether such convergence will continue into the future.

\section{Acknowledgment}

I would like to thank Leong Oi Lin, Wong Mun Yee, and Yap Li Ing for their invaluable research assistance.

Date accepted: December 2000

\section{References}

Ben David, D. (1998), "Convergence Clubs and Subsistence Economies," Journal of Development Economics 55, 155-71.

De la Fuente, A. (1997), "The Empirics of Growth and Convergence: A Selective Review," Journal of Economic Dynamics and Control 21, 23-73.

Chatterji, M. (1992), "Convergence Clubs and Endogenous Growth," Oxford Review of Economic Policy 8, 57-69.

Galor, O. (1996), "Convergence? Inferences from Theoretical Models," Economic Journal 106,1056-69.

Quah, D. (1997), "Empirics for Growth and Distribution: Stratification, Polarization, and Convergence Clubs," Journal of Economic Growth 2, 27-59.

Quah, D. (1996), "Empirics for Economic Growth and Convergence," European Economic Review 40, 1353-75.

Rassekh, F. (1998), "The Convergence Hypothesis: History, Theory and Evidence," Open Economies Review 9, 85-105.

Summers, R. and A. Heston (1991), "The Penn World Table (Mark 5): An Expanded Set of International Comparisons, 1950-1988," Quarterly Journal of Economics 105, 327368 .

Theil, H. (1967), Economics and Information Theory, Amsterdam: North Holland. 